\title{
Growth Cone Guidance by Floor Plate Cells in the Spinal Cord of Zebrafish Embryos
}

\author{
Robert R. Bernhardt, Nguyen Nguyen, \\ and John Y. Kuwada \\ Department of Biology \\ University of Michigan \\ Ann Arbor, Michigan 48109-1048
}

\section{Summary}

The spinal cord of early zebrafish embryos contains a small number of neuronal classes whose growth cones all follow stereotyped, cell-specific pathways to their targets. Two classes of spinal neurons make cell-specific turns at or near the ventral midline of the spinal cord, which is occupied by a single row of midline floor plate cells. We tested whether these cells guide the growth cones by examining embryos missing the midline floor plate cells due either to laser ablation of the cells or to a mutation (cyc-1). In these embryos the growth cones followed both normal and aberrant pathways once near the ventral midline. This suggests that normally the midline floor plate cells do provide guidance cues, but that these cues are not obligatory.

\section{Introduction}

Neuronal connections are both specific and reproducible. During development neurons establish these connections by first extending growth cones to their targets, often over considerable distances and along circuitous routes. For the most part, growth cones reach their targets by following stereotyped, cellspecific pathways. Growth cones do this by interacting with numerous components in their environment and relying on a variety of mechanisms to guide them along their pathways (Goodman et al., 1984; Landmesser, 1986; Dodd and Jessell, 1988).

Pathínding by growth cones has been analyzed in detail in the zebrafish (Brachydanio rerio) embryo, which has a simple, accessible nervous system that can be manipulated mechanically or genetically (Kimmel, 1989). Growth cones in the zebrafish embryo, generally, follow stereotyped, cell-specific pathways to their destinations. Pathfinding by the growth cones of two classes of spinal neurons, commissural primary ascending (COPA) and ventral longitudinal descending (VeLD), is particularly interesting (Kuwada et al., 1990a, 1990b; Bernhardt et al., 1990). Initially both the COPA and VeLD neurons project ventrally directed growth cones toward the floor plate from the ventral halves of their cell bodies. Floor plate cells are characteristic neuroepithelial cells that occupy the ventral midline region of spinal cords (Baker, 1927; Jessell et al., 1989). Once at the floor plate the two growth cones diverge: CoPA growth cones cross the midline, turn anteriorly, and eventually ascend in a dorsolateral tract, while VeLD growth cones turn posteriorly without crossing the midline and descend in a ventrolateral tract. This pattern of outgrowth suggests that the floor plate may play an important role for axonogenesis by these two growth cones.

The importance of the floor plate as an intermediate target for directing growth cones (Dodd and Jessell, 1988) has been demonstrated both in vitro and in vivo. In both the embryonic mammal and chick spinal cords the floor plate can attract the growth cones of commissural neurons (Tessier-Lavigne et al., 1988; Placzek et al., 1990; Bovolenta and Dodd, 1991; Yaginuma and Oppenheim, 1991). Furthermore, the floor plate may also provide contact-mediated pathfinding cues in these embryos. First, it is the site of longitudinal turns made by commissural growth cones (Bovolenta and Dodd, 1990). Second, it is the site where these axons switch from expressing one axonal adhesion molecule, TAG-1, to another, L1 (Dodd et al., 1988). Third, mouse embryos afflicted with the Danforth's short tail $(S d)$ mutation and Xenopus embryos irradiated with UV are sometimes missing the notochord and the floor plate, and concomitantly spinal axons are disarrayed (Bovolenta and Dodd, 1991; Clarke et al., 1991).

Since the floor plate is the site of cell-specific behaviors by the CoPA and VeLD growth cones in the zebrafish spinal cord, we have examined the possibility that it may be providing multiple, cell-specific guidance cues (Kuwada et al., 1990a). First, does the floor plate instruct the growth cones of CoPA and VeLD neurons to extend ventrally toward the floor plate? Second, what role does the floor plate play in the laterality of axonal trajectories, i.e., does it induce CoPA growth cones to cross the midline and prevent VeLD growth cones from doing so? Third, does the floor plate provide directionality cues so that CoPA growth cones turn anteriorly and VeLD growth cones posteriorly? We have tested these hypotheses by analyzing pathfinding in the spinal cords of the cyc-1 mutant embryos (Hatta et al., 1991), which lack uniquely identifiable floor plate cells, the midline floor plate cells, and experimental cords of wild-type embryos in which the midline floor plate cells had been ablated with a laser microbeam. We find that in the absence of the midline floor plate cells the axons of these neurons are projected from the ventral halves of their cell bodies and extend toward the ventral midline. However, once near the midline they can follow either aberrant or normal pathways (Bernhardt and Kuwada, 1990, Soc. Neurosci., abstract; Kuwada and Hatta, 1990, Soc. Neurosci., abstract). This variability is in striking contrast to the normal stereotype of axonal outgrowth. 


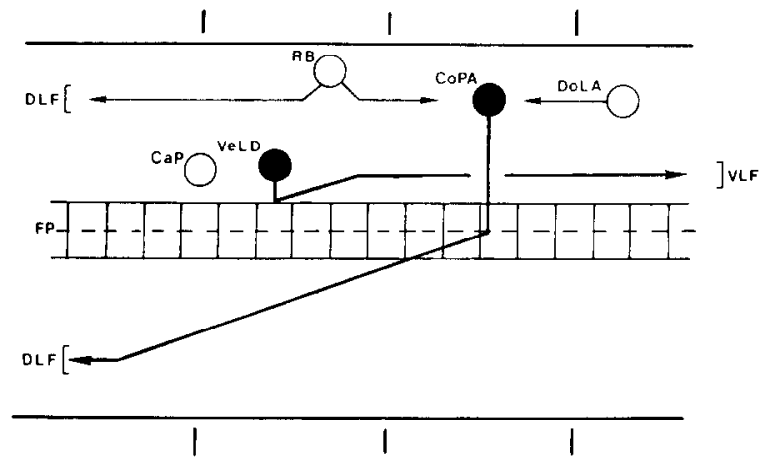

Figure 1. Schematic Diagram of the Spinal Cord in an Early Zebrafish Embryo Shown in an "Open-Book Configuration" In this configuration the spinal cord is shown as if it was cut longitudinally along the dorsal midline, opened up, and flattened. In this as in the following figures, unless noted otherwise, anterior is to the left. Five classes of neurons, the CoPA, VeLD, RB, DoLA, and CaP motor neuron; the two early longitudinal axon tracts, the DLF and ventral longitudinal fasciculus; and the midline floor plate cells are illustrated. Bars indicate segment borders, and the dashed line represents the ventral midline. One segment is approximately $50 \mu \mathrm{m}$ long.

\section{Results}

Midline Floor Plate Cells Are Specifically Missing in cyc-1 Mutant Embryos, and They Can Be Selectively Ablated with a Laser Microbeam in Wild-Type Embryos

The spinal cord in early zebrafish embryos contains a small (fewer than 10) number of neurons per hemisegment that fall into five classes that have projected growth cones by $16 \mathrm{hr}$ postfertilization (PF) (Myers et al., 1986; Bernhardt et al., 1990: Kuwada et al., 1990b) (Figure 1). Of the five classes of early neurons the growth cones of the CoPA and VeLD neurons exhibit cell-specific behaviors near the ventral midline $\mathrm{Ku}$ wada et al., 1990a). The ventral midline region consists of a row of neuroepithelial cells, approximately three cells wide in cross section, that run along the anteriorposterior axis and are bounded by longitudinal tracts (Kuwada et al., 1990a). The middle cell, which straddles the ventral midline, is a large cell, easily distinguished with differential interference contrast optics in living embryos (Figure 2A). The midline cell is antigenically distinct from other spinal cells (Hatta et al., 1991) and can be distinguished from other neuroepithelial cells by labeling them with the monoclonal antibody (MAb) RMO-270 (Figure 2B), which recognizes the intermediate molecular weight neurofilament in mammals (Szaro et al., 1989). MAb RMO-270 recognizes neurons and the midline cells but not other cells, including the cells lateral to the midline cells in the spinal cord of zebrafish embryos (data not shown). The floor plate has been identified as consisting of only the middle cell (Hatta et al., 1991) or as consisting of all three cells in the ventral midline region (Kuwada et al., 1990a). This paper treats the
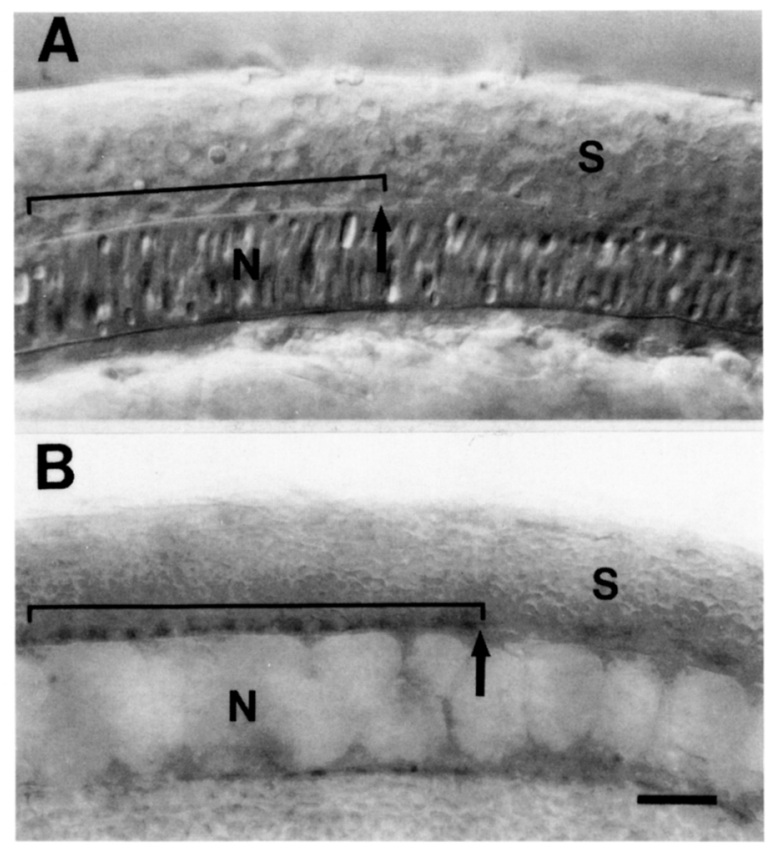

Figure 2. Midline Floor Plate Cells Can Be Ablated with a Laser Microbeam

Differential interference contrast micrographs slowing a side view of a whole-mounted embryo (A) $10 \mathrm{~min}$ and (B) $10 \mathrm{hr}$ following ablation of the midline floor plate cells posterior to the arrow at $16 \mathrm{hr}$ PF. (A) The midline floor plate celis can be seen as a row of large nuclei denoted by a bracket at the ventral midline of the spinal cord (S) just dorsal to the notochord $(N)$ in control segments. No large nuclei are visible in experimental segments posterior to the arrow. (B) MAb RMO-270 labels the midline floor plate cells denoted by a bracket in control segments. No labeling is seen in experimental segments posterior to the arrow. Scale for (A) and (B), $20 \mu \mathrm{m}$.

floor plate as consisting of the midline and two lateral cells.

Examination of semithin and ultrathin sections of the cord revealed that the midline floor plate cell is trapezoidal in cross section, with a horizontally aligned nucleus and a distinct, electron lucent cytoplasm (Figure 3A). These cytological features distinguish the midline floor plate cell from other spinal cells. CoPA growth cones insert between the base of the midline floor plate cell and the well-developed basal lamina that separates the cord from the notochord (Figure 3D). The close apposition of the growth cone with the midline floor plate cell suggests the possibility of a contact-mediated action of the midline floor plate cells for axonal guidance.

The cyc-1(b16) mutation of zebrafish results in a pleiotropic recessive phenotype that is at least $92 \%$ penetrant and includes the deletion of the midline floor plate cells thoughout the rostrocaudal extent of the mutant cord (Hatta et al., 1991). Although the distribution of some cells normally found in the ventral cord, such as the primary motor and VeLD neurons, is unaffected by the mutation (see below), the fate of the lateral floor plate cells could not be deter- 

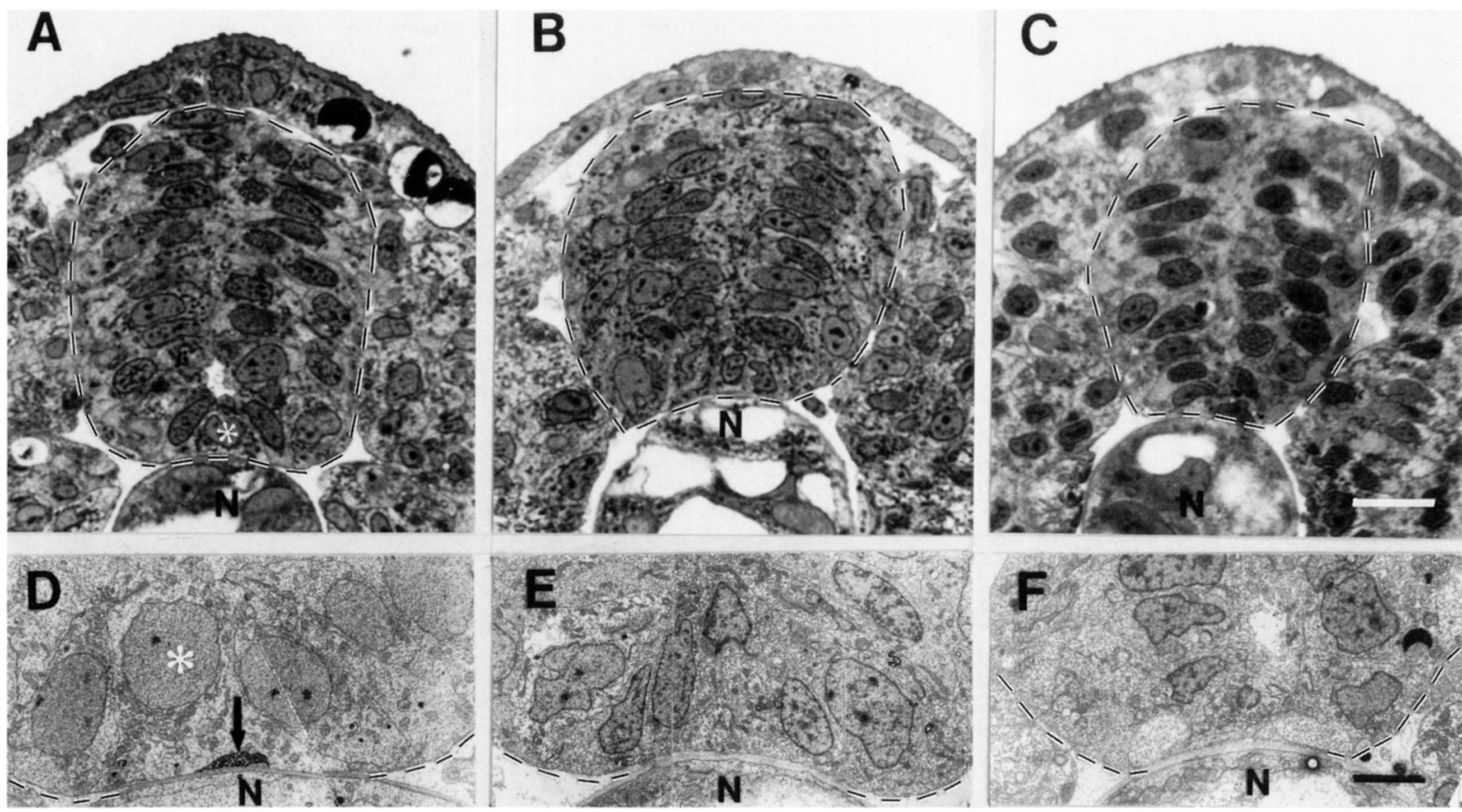

Figure 3. The Midline Floor Plate Cells Are Selectively Eliminated in cyc-1 Embryos and by Laser Ablation in Wild-Type Embryos Light (A-C) and electron (D-F) micrographs of cross-sectioned spinal cords of an 18 hr PF wild-type embryo (A and D), cyc-1 embryo ( $B$ and $E$ ), and wild-type embryos following laser ablation of the midline floor plate cells at 16 hr PF (C and F). The unique midline floor plate cell (the nucleus is denoted by an asterisk) seen in a wild-type cord ( $A$ and $D$ ) is missing in cyc- 7 ( $B$ and $E$ ) and after laser ablation ( $C$ and $F$ ). Apart from the absence of the midline floor plate cell, the cord appears normal and is relatively free of degeneration products at $18 \mathrm{hr}$ in both cyc- 7 (E) and after laser ablation (F). In (D) a photooxidized LY-labeled CoPA growth cone can be seen inserted between the midline floor plate cell and the basal lamina separating the cord from the notochord $(\mathrm{N})$. The margins of the cord are designated by dashed lines. Scale for (A)-(C), $10 \mu \mathrm{m}$; (D)-(F), $5 \mu \mathrm{m}$.

mined, since presently there are no markers for these cells. Therefore, the cyc-1 mutation either deletes the midline floor plate cell or deletes the midline cell and one or both of the lateral floor plate cells.

Light and electron microscopic examination of cyc- 1 cords demonstrates that other neuroepithelial cells occupy the ventral midline, and the overall organization of the mutant cord appears normal (Figures $3 \mathrm{~B}$ and $3 \mathrm{E}$ ). Relatively large, laterally located cell bodies are found in locations normally occupied by motor or VeLD neurons in the ventral cord and by CoPA, dorsal longitudinal ascending (DoLA), and Rohon-Beard (RB) neurons in the dorsal cord (Bernhardt et al., 1990). Inspection of electron micrographs (from 13 segments in 4 embryos) revealed no signs of degeneration at the ventral midline during the time period ( 18 hr) when CoPA growth cones normally reach the floor plate region (Figure $3 \mathrm{E}$ ).

The midline floor plate cells can be specifically ablated with a laser microbeam in wild-type embryos (see Experimental Procedures). Differential interference contrast inspection of living embryos 5-15 min after laser ablation showed that the distinct row of midline floor plate cells was missing in experimental segments (Figure 2A). This was confirmed by labeling experimental animals with MAb RMO-270 and by light and electron microscopic sections of experimental segments (Figure 2B; Figures $3 \mathrm{C}$ and $3 \mathrm{~F}$ ). Furthermore, these sections demonstrated that there was no generalized damage to the cord following ablation of the midline floor plate cells. Ventrolateral cells, presumably motor neurons or VeLD interneurons, were present as well as the distinct basal lamina separating the spinal cord from the notochord. Importantly, other cells in the ventral cord, such as the identified motor neurons, were normal (see below).

\section{CoPA and VeLD Axons Follow Either Abnormal or Normal Trajectories in the Absence of the Midline Floor Plate Cells}

Spinal neurons were labeled (see Experimental Procedures for details) by intracellular injection of Lucifer yellow (LY) dye, hacklabeling with the dil (1,1'-dioctadecyl-3,3,3',3'-tetramethylindocarbocyanine perchlorate) dye (Honig and Hume, 1986), application of MAb CON1 (Bernhardt et al., 1990), and application of a MAb against acetylated $\alpha$-tubulin (Piperno and Fuller, 1985). CoPA neurons are antigenically distinct from other spinal neurons in the early spinal cord and can be labeled with MAb CON1 within 1 and 2 hr of growth cone extension (Bernhardt et al., 1990; Kuwada et al., 1990b). The MAb against acetylated $\alpha$-tubulin labels most if not all zebrafish neurons (Bernhardt et al., 1990; Chitnis and Kuwada, 1990, 1991). Axonal trajecto- 
Table 1. Number of CoPA Neurons with Normal and Abnormal Trajectories in cyc-1 Embryos and Wild-Type Embryos Following Laser Ablation of the Midline Floor Plate Cells

\begin{tabular}{|c|c|c|c|c|c|c|}
\hline & Normal & $\begin{array}{l}\text { Ventral/ } \\
\text { Ascending }\end{array}$ & $\begin{array}{l}\text { Ipsilateral/ } \\
\text { ^scending }\end{array}$ & $\begin{array}{l}\text { Contralateral/ } \\
\text { Descending }\end{array}$ & $\begin{array}{l}\text { Ipsilateral/ } \\
\text { Descending }\end{array}$ & Other \\
\hline cyc-1 & $86(43 \%)$ & $49(24 \%)$ & $45(22 \%)$ & $2(1 \%)$ & $3(2 \%)$ & $16(8 \%)$ \\
\hline Laser ablated & $N^{c}$ & 32 & 15 & 11 & 3 & 2 \\
\hline
\end{tabular}

Ventral/ascending CoPA neurons had an axon that ascended in the ventral half of the cord for an abnormally long distance (see text) ${ }^{b}$ Other category consists of CoPA neurons with axons that crossed the midline and bifurcated $(n=2)$, exited the spinal cord $(n=2$ one ipsilaterally and one contralaterally), ascended contralaterally but looped or kinked near the ventral midline $(\mathrm{n}=10)$, or projected 2 axons ( $n=2$; one ascended contralaterally, the other ipsilaterally).

c Total number of normal CoPA neurons was not recorded. However, normal CoPA neurons were found following laser ablation of the midline floor plate cells. At least 6 normal CoPA neurons were found to be bilateral homologs of aberrant CoPA neurons.

Table 2. Number of VeLD Neurons with Normal and Abnormal Trajectories in cyc-1 Embryos and Wild-Type Embryos following Laser Ablation of the Midline Floor Plate Cells

\begin{tabular}{llllll}
\hline & Normal & $\begin{array}{l}\text { Ipsilateral/ } \\
\text { Ascending }\end{array}$ & $\begin{array}{l}\text { Contralateral/ } \\
\text { Ascending }\end{array}$ & $\begin{array}{l}\text { Contralateral/ } \\
\text { Descending }\end{array}$ \\
\hline${\text { cyc- } 7^{\mathrm{a}}}^{\text {Baser ablated }}{ }^{\mathrm{b}}$ & $37(67 \%)$ & $9(16 \%)$ & $2(4 \%)$ & $6(11 \%)$ & $1(2 \%)$ \\
\hline
\end{tabular}

a VeLD neurons were assayed by labeling with either $L Y(n=34)$ or dil $(n=21)$. Since the midline floor plate cells are missing from all the spinal segments in cyc-1 embryos, assaying VeLD neurons with a single injection of dil should be comparable to assaying with LY. In fact $35 \%$ of LY-labeled and $29 \%$ of dil-labeled VeLD neurons were aberrant. Therefore, the data were combined.

${ }^{b}$ VeLD neurons were assayed by dil backlabeling from an injection site either anterior $(n=21)$ or posterior $(n=6)$ to the experimental segments. Therefore, the proportion of normal to aberrant VeLD neurons between cyc-1 and laser-ablated embryos cannot be compared. In 6 of these embryos dil injections were made both anterior and posterior to the experimental segments: 2 of the 10 Vel $D$ neurons labeled had ipsilateral, ascending axons, while the others were normal.

ries in the absence of the midline floor plate cells were examined at $18-28 \mathrm{hr}$ PF in 114 cyc- 1 embryos and 63 wild-type embryos following laser ablation of the midline floor plate cells at the time of or prior to axonal outgrowth by the CoPA and VeLD neurons. The trajectory of each labeled neuron could be unambiguously followed in whole-mounted embryos by focusing on the axon through different focal planes with a compound microscope.

\section{CoPA Neurons}

Of the 201 CoPA neurons labeled with LY or MAb CON1 that could be unambiguously traced in cyc-1 embryos, $57 \%$ had axons that followed abnormal trajectories, and $43 \%$ had axons that followed the normal trajectory (Table 1; Figure 4). The proportions of normal to abnormal CoPA neurons assayed by LY or MAb CON1 were comparable. Similarly, CoPA neurons had both normal and aberrant axons following laser abla- tion of the midline floor plate cells in wild-type embryos (Table 1). Although the total number of normal CoPA neurons following laser ablation was not recorded, normal CoPA neurons were found. At least 6 normal CoPA neurons were bilateral homologs of aberrant CoPA neurons. The growth cones of these normal neurons probably encountered the same environment at the ventral midline as the aberrant homologs.

It is not likely that axonal errors were due to some systematic variability between cyc-1 embryos, since both aberrant and normal trajectories were found in the same embryos. The variability of trajectories contrasts with the stereotyped trajectory found normally: only $1 \%$ of CoPA neurons $(n=192)$ had abnormal axons in wild-lype embryos.

\section{VeLD Neurons}

Of 55 Vel. neurons assayed in cyc-1 embryos, $33 \%$

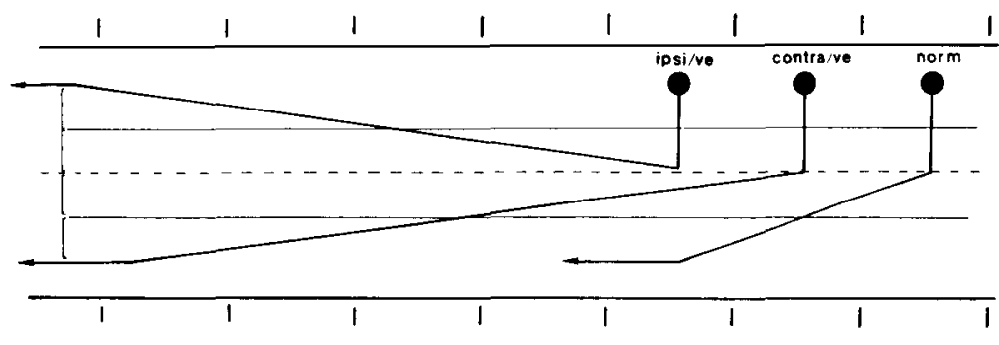

Figure 4. Schematic Diagram Showing the Three Most Common Trajectories of CoPA Axons Observed in the Absence of the Midline Floor Plate Cells

The spinal cord is represented in the "open-book configuration." Some axons (norm) appeared normal: they crossed the ventral midline (dashed line), turned anteriorly, and reached the point (thin line) halfway between the ventral midline and the DLF after approximately 1 segment. A second class of axons (contra/ve) crossed the midline and turned anteriorly, but reached the halfway point after approximately 2.8 segments A third class of axons (ipsi/ve) turned anteriorly before crossing the midline and reached the halfway point after approximately 2.5 segments. 

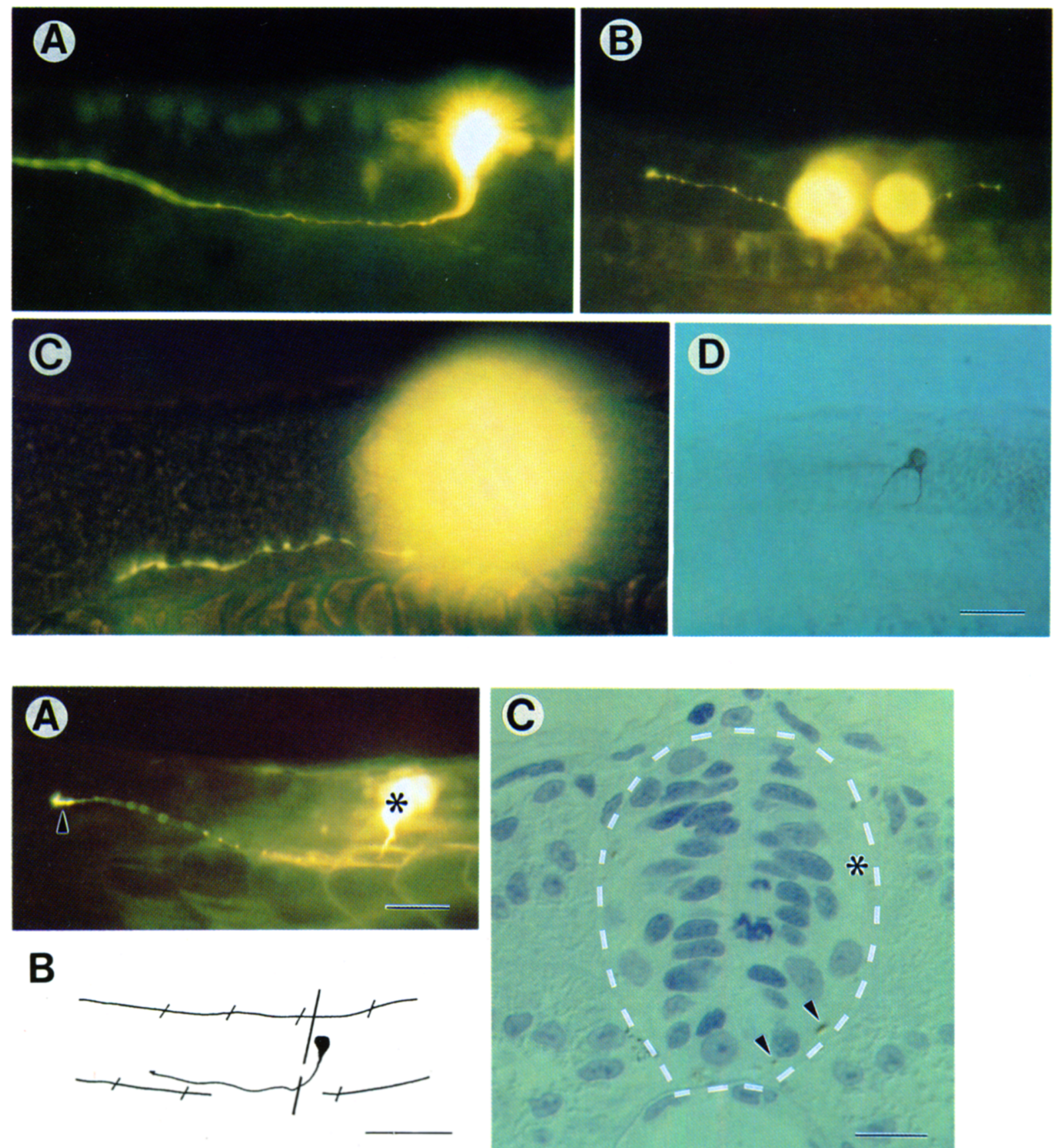

Figure 5. Aberrant and Normal CoPA Neurons Labeled with LY or MAb CON1 Shown in Side Views of Whole-Mounted cyc-1 Embryos

(A) A CoPA neuron with an abnormal ipsilateral, ascending axon in a $26 \mathrm{hr}$ embryo. Note that the cell body is approximately in the same focal plane as the ascending axon. (B) A normal CoPA neuron with a contralateral, ascending axon (left) and an aberrant CoPA neuron with a contralateral, descending axon (right) in a $21 \mathrm{hr}$ embryo. The contralateral cell bodies appear very large because they are out of the focal plane of this and the following micrograph. (C) An aberrant CoPA neuron with a growth cone extending anteriorly in the ventral cord in a $20 \mathrm{hr}$ embryo. (D) An aberrant CoPA neu ron with two axons, one was ipsilateral, ascending and the other contralateral, ascending in a $26 \mathrm{hr}$ embryo. Scale for (A), (C), and (D), $25 \mu \mathrm{m}$; (B), $50 \mu \mathrm{m}$.

Figure 6. Aberrant CoPA Neurons following Laser Ablation of the Midline Floor Plate Cell at 14-16 hr PF in Wild-Type Embryos (A) A CoPA neuron (asterisk) with an ipsilateral, ascending axon and growth cone (arrowhead) labeled with LY shown in a sideview of a whole-mounted $24 \mathrm{hr}$ embryo. Scale, $50 \mu \mathrm{m}$. (B) Camera lucida drawing of an ipsilateral, ascending CoPA neuron labeled with $\mathrm{MAb}$ CON1 shown in a side view from a $27 \mathrm{hr}$ PF embryo. Arrowhead at the end of the axon denotes that the axon ascended beyond the limits of the drawing. Line through the neuron indicates the level of the cross section shown in (C). Scale, $50 \mu \mathrm{m}$. (C) Cross section showing that the CoPA axon shown in (B) approaches the ventral midline in a region of the cord devoid of the midline floor plate cell. Portions of the MAb CON1-labeled axon are indicated by arrowheads. The cord is outlined by dashed lines, and the approximate position of the COPA cell body is denoted by an asterisk. The two large cell bodies at the ventral floor of the cord have the shape and the lightly labeled nuclei that are characteristics of neurons. The midline floor plate cell has a trapezoidal shape and a flattened nucleus (see Figure 3). Examples of other neurons can be seen in the lateral cord dorsal to these ventral cell bodies. Scale, $10 \mu \mathrm{m}$. 

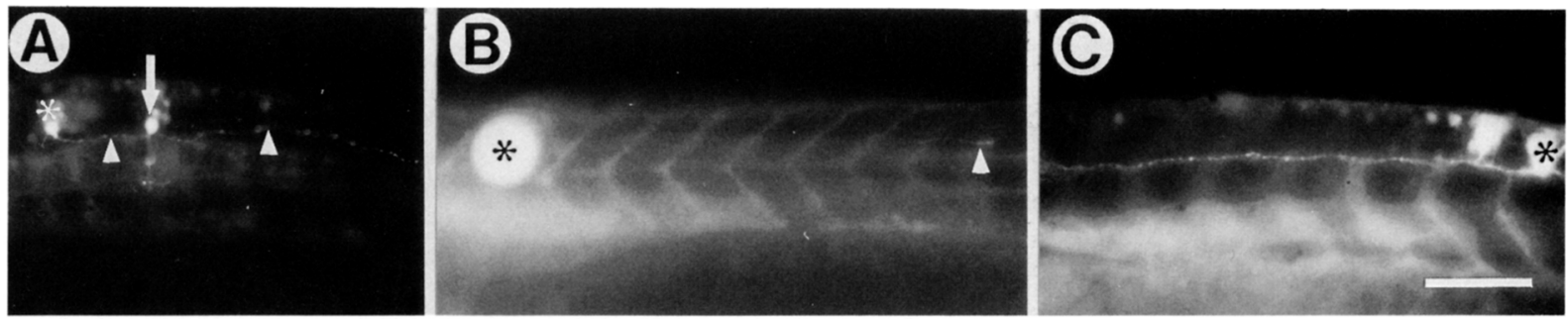

Figure 7. Normal and Abnormal VeLD Neurons Labeled with LY Shown in Side Views of Whole-Mounted cyc-1 Embryos at 27 Hr PF (A) A VelD neuron (asterisk) with a normal axon (arrowheads). The cell body is out of the focal plane. Arrow denotes a normal CaP motor neuron. (B) An abnormal VeLD neuron with a growth cone (arrowhead) that is descending contralateral to its cell body, which is out of the focal plane. The borders of the metamerically arranged axial muscles can also be seen. (C) An abnormal VeLD neuron with an ipsilateral, ascending axon. The growth cone of this neuron crossed the midline and extended anteriorly on the contralateral side beyond the limit of the micrograph. LY-labeled neuron anterior to the VeLD neuron was a normal CoPA neuron. Scale for (A)-(C), $100 \mu \mathrm{m}$.

had aberrant axons, while $67 \%$ had normal axons (Table 2). As with cyc- 1 embryos, VeLD neurons had axons with either normal or aberrant trajectories following ablation of the midline floor plate cells in wild-type embryos (Table 2).

\section{CoPA and VeLD Axons Project Normally to the Ventral Midline Despite the Absence of the Midline Floor Plate Cells \\ CoPA Neurons}

The axons of nearly all CoPA neurons assayed in cyc-1 embryos and following laser ablation of the midline floor plate cells in wild-type embryos were projected correctly from the ventral poles of their cell bodies and ran ventrally along the margin of the spinal cord toward the ventral midline (Figure 4; Figure 5; Figure 6). These axons always ran to within $10 \mu \mathrm{m}$ of the ventral midline (Figure $6 \mathrm{C}$ ) and often ran to the ventral midline. In two cases cyc-1 CoPA neurons projected two axons: one that ran correctly and the other that ran first anteriorly then ventrally (Figure 5D).

\section{VeLD Neurons}

Similarly all VeLD axons assayed in cyc- 1 embryos and following laser ablation of the midline floor plate cells were projected from the ventral halves of their cell bodies (Figure 7). These results demonstrate that the ventral midline cell is not necessary for projection of axons from the ventral halves of CoPA and VeLD neurons and their subsequent extension to the ventral midline region.

\section{Many but Not All CoPA and VeLD Axons Make Laterality Errors in the Absence of the Midline Floor Plate Cells CoPA Neurons}

CoPA axons either crossed the midline or turned inappropriately within $10 \mu \mathrm{m}$ of the midline on the ipsilateral side of the spinal cord and failed to cross the midline in the absence of the midline floor plate cells. In cyc- 1 embryos the axons of $74 \%$ of CoPA neurons crossed the midline, while $26 \% \operatorname{did}$ not (Table 1; Figure 4; Figure 5).
Laser ablation of midline floor plate cells in wildtype embryos prior to axonogenesis affected the CoPA growth cones in a manner roughly similar to that seen in cyc- 1 embryos. Again axons either crossed the midline or failed to do so by turning within $10 \mu \mathrm{m}$ of the midline on the ipsilateral side of the spinal cord (Table 1). Of CoPA neurons that made errors following laser ablation of the midline floor plate cells and in cyc- 1 embryos, $29 \%$ and $44 \%$, respectively, projected axons that failed to cross the midline. We confirmed that the midline floor plate cells were successfully eliminated in experimental segments containing aberrant CoPA axons by examining sections of the cord at or near the sites the axons approached the ventral midline ( $n=6$; Figures $6 \mathrm{~B}$ and $6 \mathrm{C}$ ).

\section{VelD Neurons}

In the absence of the midline floor plate cells the axons of VeLU neurons now sometimes inappropriately crossed the midline. In cyc- 1 embryos $15 \%$ of $L Y$ or dil-labeled VeLD axons crossed the midline, while 85\% did not (Table 2; Figure 7). Following laser ablation of the midline floor plate cells the relatively small sample of VeLD axons did have aberrant trajectories (see below), but all the axons remained ipsilateral. These results suggest that the midline floor plate cells do participate in normally inducing CoPA growth cones to cross the ventral midline and keeping VeLD growth cones from crossing the midline.

\section{CoPA and VeLD Axons Occasionally Make \\ Directionality Errors in the Absence of the Midline Floor Plate Cells CoPA Neurons}

Counting both normal and aberrant CoPA neurons $91 \%$ of CoPA neurons had axons that turned anteriorly near the ventral midline, and $9 \%$ turned in an aberrant direction in cyc-1 embryos (Table 1; Figure 5). Axons that turned in an aberrant direction included those that turned posteriorly, bifurcated, and extended anteriorly and posteriorly, turned to exit the spinal cord, and initially turned posteriorly but then reversed direction by forming a loop or kink to run anteriorly 

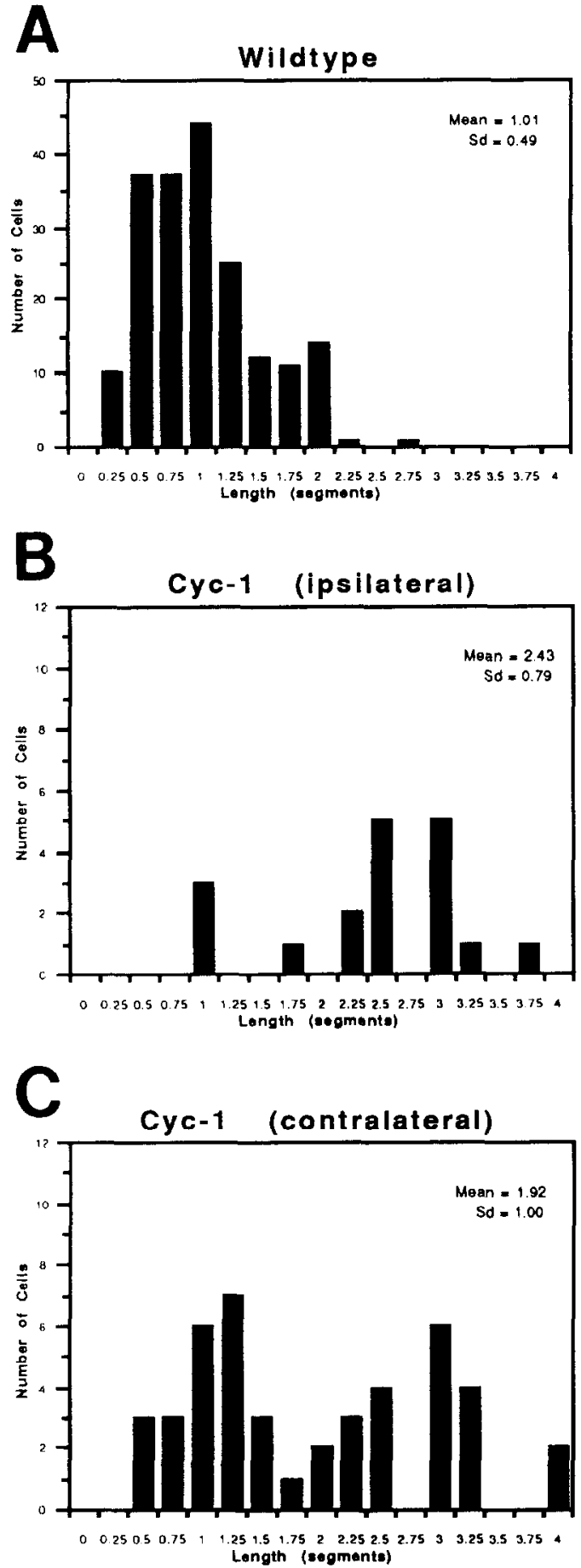

Figure 8. The Trajectories of the Ascending Portions of CoPA Neurons Are More Variable in cyc- 7 Compared with Wild-Type Embryos

Histograms showing that the distance (in fractions of spinal segments) over which MAb CON1-labeled CoPA axons extended anteriorly before reaching the halfway point between the ventral midline and the DLF (see text) in wild-type embryos (A) and in ipsilateral, ascending (B) and contralateral, ascending (C) CoPA neurons in cyc-1 embryos. The distances for jpsilateral, ascending and contralateral, ascending axons in cyc- 1 embryos differed significantly from that in wild-type embryos (see Experimental Procedures) eventually. As in cyc-1 embryos CoPA axons turned anteriorly and in an aberrant direction following laser ablation of the midline floor plate cells. Of the CoPA axons that made errors in cyc-1 embryos and following laser ablation of the midline floor plate cells in wild-type embryos, $18 \%$ and $24 \%$, respectively, turned in an aberrant direction rather than anteriorly (Table 1; Figure 5).

\section{VeLD Neurons}

In cyc- 7 embryos $22 \%$ of VeLD neurons had axons that inappropriately turned anteriorly rather than posteriorly (Table 2; Figure 7). The proportions of VeLD axons that turned anteriorly labeled with $L Y$ and dil were comparable. Following laser ablation of the midline floor plate cells in wild-type embryos, VeLD axons turned either anteriorly or posteriorly (Table 2; Figure 7 ).

\section{Once at the Ventral Midline CoPA Axons \\ Often Ascend Abnormally in \\ the Ventral Spinal Cord}

All CoPA axons that ascended following laser ablation of the midline floor plate cells and in cyc-1 embryos eventually reached and ascended in the dorsal longitudinal fasciculus (DLF), the appropriate tract, but the distance the axons extended in the ventral half of the cord was much more variable than in wild-type embryos (Table 1; Figure 8; see Experimental Procedures). Normally CoPA axons extend in the ventral half of the cord for approximately 1 segment with $99 \%$ extending in the ventral half of the cord for no more than 2 segments. Following laser ablation of the midline floor plate cells in wild-type embryos, the most common aberrant CoPA axons were those that crossed the ventral midline and turned anteriorly, but remained in the ventral cord for greater than 2 segments. Similarly contralateral, ascending CoPA axons in cyc-1 embryos extended in the ventral half of the cord for approximately twice the distance of normal CoPA axons (see Experimental Procedures for more details). In fact these axons appeared to fall into two populations: $57 \%$ extended in the ventral cord like wild-type CoPA neurons (no more than 2 segments) but $43 \%$ extended in the ventral cord for a much longer distance (greater than 2 segments; average distance $=2.8$ segments) than normal. These latter axons were the most frequent aberrant axons and accounted for $24 \%$ of all CoPA axons assayed in cyc- 1 embryos. Concordantly, some CoPA neurons had growth cones that ascended along a ventrolateral pathway rather than toward the DLF when assayed shortly after these growth cones normally reach the ventral midline (Figure $5 \mathrm{C}$ ).

The ipsilateral, ascending CoPA axons in cyc- $1 \mathrm{em}$ bryos also extended in the ventral half of the cord more than twice the distance of normal CoPA axons. In these cases as well as with contralateral, ascending axons, it appeared that the axons ran parallel to the ventral midline, and once the axon extended toward the DLF the angle of ascent was shallower. 

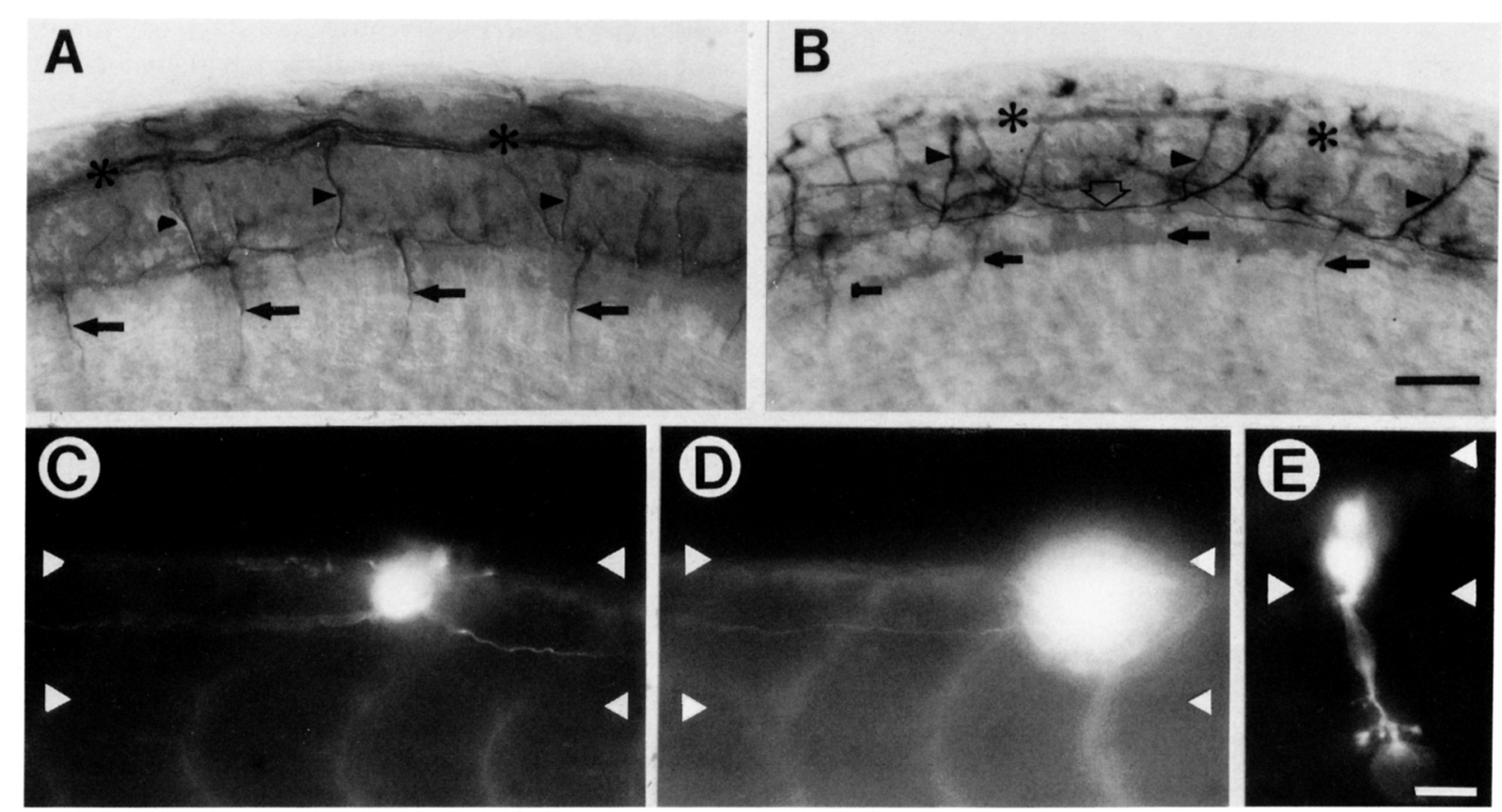

Figure 9. The Overall Organization of the Cord Is Normal in Embryos Missing the Midline Floor Plate Cell

Axons labeled with the MAb against acetylated tubulin show that the DLF (asterisks) and ventral roots (arrows) are normal in 22 hr PF cyc-1 embryos $(A)$ and wild-type embryos following laser ablation of the midline floor plate cells (B). Commissural axons extending from the dorsally located cell bodies to the ventral midline are denoted by arrowheads in (A) and (B). Open arrow denotes a CoPA axon that is ascending ipsilateral to its cell body following laser ablation of the midline floor plate cells (B). Scale for (A) and (B), $25 \mu \mathrm{m}$. I $\mathrm{Y}$-injected $\mathrm{RB}$ (C), DoLA (D), and CaP motor (E) neuron with normal axons in cyc-1 embryos at $23 \mathrm{hr}, 23 \mathrm{hr}$, and $20 \mathrm{hr}$ PF, respectively. Arrowheads denote dorsal and ventral border of the cord in $(C)-(E)$. Scale for $(C)-(E), 25 \mu \mathrm{m}$.

Other Spinal Neurons Are Normal in cyc-1 Embryos and in Wild-Type Embryos following Ablation of the Midline Floor Plate Cells

Inspection of cross sections indicated that, apart from the floor plate deficit, there was no gross disruption of the organization of mutant and experimental cords (see above). We confirmed that neurons other than CoPA and VeLD were normal in cyc- 1 mutant and experimental spinal cords (Figure 9). All the neuronal classes normally found in the early spinal cord were found in both cyc- 1 and experimental cords. Examination of embryos labeled with the MAb against acetylated $\alpha$-tubulin ( $n=22$ for $c y c-1 ; n=26$ for experimental) demonstrated that the DLF was present, and neurons normally found in the dorsal half of the cord (RB neurons and all the classes of commissural neurons including CoPA [see Bernhardt et al., 1990]) were located in their correct positions and in cyc- 7 embryos in the correct numbers (Table 3). LY and dil labeling of $\mathrm{KB}$ and DoLA neurons reinforced the acetylated tubulin results and demonstrated that their axons were normal in both cyc-1 (44 RB and 9 DoLA; Figure 9) and experimental (12 RB; data not shown) embryos. Likewise, spinal motor neurons in the ventral cord were for the most part normal both in cyc- 1 embryos (Eisen, 1991; Figure 9E) and in experimental segments of wild-type embryos. Twenty-eight of 30 and 4 of 4 caudal primary $(\mathrm{CaP})$ motor neurons labeled with $L Y$ had normal trajectories in cyc-1 embryos and in wildtype embryos following laser ablation, respectively. These observations strongly suggest that the direct effect of the cyc-1 mutation and of the laser ablations was restricted to the ventral midline and strengthen the conclusion that the abnormal CoPA and VeLD axon trajectories are due to the floor plate deficit.

\begin{abstract}
Abnormal Axon Trajectories Are Due to the Absence of the Midline Floor Plate Cells

To test whether the pathfinding errors were due to the removal of the midline floor plate cells or alternatively could be brought about by the elimination of any ventrally located cells along the CoPA axon trajectory, we performed two sets of cuntrol ablations (see Experimental Procedures). The first set $(n=14)$ removed cells at the level of the primary motor and Vel $D$ neu-
\end{abstract}

\begin{tabular}{|c|c|c|c|c|}
\hline & \multicolumn{2}{|l|}{ RB } & \multicolumn{2}{|c|}{ Commissural } \\
\hline & Mean & Range & Mean & Range \\
\hline Wild type $(n=4)$ & 10.2 & $8-12$ & 17.1 & 1519 \\
\hline$c y c-7(n=5)$ & 10.2 & $8-12$ & 16.5 & $15-21$ \\
\hline
\end{tabular}
Neurons of All Classes in Segments 7-9 (Three Hemisegments) from Wild-Type and cyc-1 Embryos at $28 \mathrm{Hr} \mathrm{PF}$ 


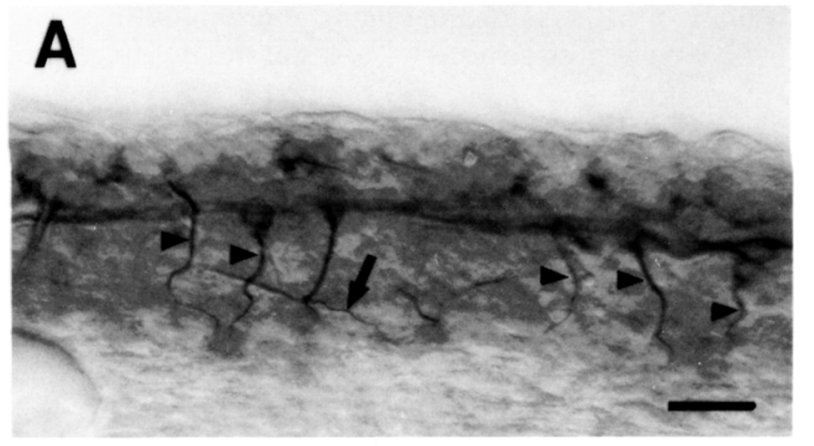

B

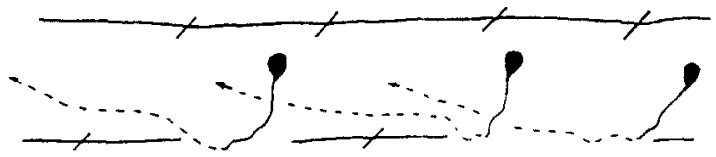

Figure 10. Laser Ablation of Cells Lateral to the Midline Floor Plate Cells in Wild-Type Embryos Does Not Induce Pathfinding Errors (A) Six hours following unilateral ablation of all cells at the level of the VeLD and motor neurons at $16 \mathrm{hr} P F$, commissural axons (arrowheads) labeled with the MAb against acetylated tubulin ran down to the ventral midline and disappeared out of the focal plane as they crossed the midline. Subsequently these axons turned anteriorly and followed their normal trajectory to the DLF on the other side. A commissural axon originating from the contralateral side has crossed the midline and turned anteriorly onto its normal diagonally ascending pathway (arrow). The ventral roots are missing, since the motor neurons had been laser ablated. Scale, $25 \mu \mathrm{m}$. (B) Camera lucida drawings of MAb CON1-labeled CoPA neurons in a $27 \mathrm{hr}$ embryo in which the floor plate cell just lateral to the midline floor plate cell was laser ablated $10 \mathrm{hr}$ earlier. The contralateral portions of the axons are denoted as dashed lines. Scale, $50 \mu \mathrm{m}$.

rons on one side, i.e., two to three cells lateral to the midline floor plate cell in wild-type embryos. The second set of control ablations $(n=10)$ removed lateral floor plate cells on one side of the midline floor plate cells in wild-type embryos. Despite these lesions along their normal pathway all CoPA axons were normal (Figure 10). These results demonstrate that CoPA growth cones can apparently cross a lesion site without any incidence of pathfinding errors and that a mere spatial rearrangement of cells in the ventral cord that could result following removal of ventral cells (including the midline floor plate cell) is not sufficient to cause the pathfinding errors.

Although removal of one of the lateral floor plate cells was not sufficient to induce pathfinding errors, it was still possible that the variable behavior of growth cones in the absence of the midline cell could be due to a quantitative decrease in a cue normally provided by all three floor plate cells. To examine this two more sets of laser ablations were performed. In one set all three floor plate cells were eliminated in wild-type embryos $(n=13)$. In the other set the two cells found on either side of the ventral midline that might be lateral floor plate cells were removed in cyc-7 embryos
( $n=19$ ). If variability was due to a quantitative decrease in a pathfinding cue provided by all the floor plate cells, then one might expect to see a higher rate of errors following removal of all three cells. This apparently is not the case, since in all cases CoPA growth cones extended to the ventral midline, and once at the midline their error rate was not significantly higher than that seen in unmanipulated cyc-1 embryos (Table 4). One interpretation of these ablation experiments is that the lateral floor plate cells are not critical for axonal guidance near the ventral midline. However, an alternative interpretation that depends on induction of the lateral floor plate cells by the midline cell is also possible (see Discussion). In any case, our results strongly suggest an important role of the midline floor plate cell for guidance of spinal growth cones.

\section{Discussion}

The Midline Floor Plate Cells Guide Growth Cones Near the Ventral Midline

Analysis of the spinal cords in cyc-1 embryos and in wild-type embryos following laser ablation of the mid-

Table 4. Comparison of the Number and Proportion of Normal to Aberrant CoPA Axons Labeled with MAb CON1 in cyc-1 Embryos with That following Ablation of the Two Ventral Midline Cells in cyc-1 Embryos and Ablation of All Three Floor Plate Cells in Wild-Type Embryos

\begin{tabular}{lll}
\hline & Normal Axons & Aberrant Axons \\
\hline cyc- $1(n=23$ embryos) & $64(47 \%)$ & $72(53 \%)$ \\
cyc- 1 , two ventral midline cells ablated $(\mathrm{n}=19$ embryos) & $15(32 \%)$ & $32(68 \%)$ \\
Wild type, all floor plate cells ablated $(\mathrm{n}=13$ embryos) & $25(58 \%)$ & $18(42 \%)$ \\
\hline
\end{tabular}

The proportions were arc sine-transformed and the means compared with the Student's t test. Neither the proportions following ablations in cyc-1 nor in wild-type embryos were significantly different from the proportions in unmanipulated cyc-7 embryos: for ryc-1 ablated versus $c y c-1 \mathrm{t}=0.87, \mathrm{df}=40, \mathrm{P} \leqslant 0.125$; for wild type ablated versus cyc-1 $\mathrm{t}=0.79, \mathrm{df}=34, \mathrm{P} \leqslant 0.20$. 
line floor plate cells provides two independent lines of evidence for an important role of the midline floor plate cell in guiding a subset of spinal growth cones. First, in both mutant and experimental spinal cords a dramatic increase in pathfinding errors is correlated with the absence of the midline floor plate cells. Second, laser ablation of other ventral cells and the analysis of cyc-1 cords strongly suggest that the aberrant pathways taken by identified growth cones are not an artifact of the laser ablation procedure nor due to a mere rearrangement of cells in the ventral cord. Third, a direct effect of the mutation on CoPA and VeLD neurons is not necessary for pathfinding errors, since the laser ablation of midline floor plate cells in wildtype embryos is sufficient to phenocopy CoPA and $V c L D$ axons in cyc- 1 embryos. Therefore, the simplest interpretation of our results is that the errors in axonal pathfinding are the direct result of the absence of the midline floor plate cells. These observations are consistent with a model proposing that the midline floor plate cells have multiple, cell-specific actions on spinal growth cones (Kuwada et al., 1990a). In support of this model, mistakes in axonal pathfinding by reticulospinal neurons have also been observed both in the cyc- 1 embryos and after floor plate ablations in the hindbrain of wild-type embryos (Hatta et al., 1990, Soc. Neurosci., abstract).

What role the lateral floor plate cells play in guiding growth cones depends on whether the midline floor plate cells normally induce the lateral floor plate cells or not. Ablation of the lateral floor plate cells on one side of the cord produced no errors in axonal outgrowth, and elimination of all the floor plate cells produced no more errors than elimination of the midline floor plate cells alone. If the lateral cells are not induced by the midline floor plate cell, then our experiments suggest that the lateral cells do not provide significant guidance cues. On the other hand if the midline floor plate cells are capable of inducing the lateral floor plate cells, then elimination of the midline cell by the cyc- 1 mutation or by our laser ablations may have eliminated all the floor plate cells, and ablation of one lateral floor plate cell may have led to induction of a new lateral floor plate cell. In this case, no conclusions regarding the guidance function of lateral floor plate cells could be inferred from our experiments. Although it is not known whether lateral floor plate cells are induced by the midline floor plate cells, homengenetic induction of midline floor plate cells by other midline floor plate cells does occur in the zebrafish spinal cord (Hatta et al., 1991). However, the possibility that such induction may have been a factor is perhaps unlikely in our ablation experiments, since the midline cells were ablated relatively late (just $0-2$ hr prior to axonal outgrowth), at a time when the midline floor plate cells may no longer be capable of inducing lateral cells.

How might the floor plate affect growth cones in the region of the ventral midline? In the rat spinal cord commissural growth cones traverse the floor plate along a pathway orthogonal to the longitudinal axis and make precise anterior turns at the boundary between the floor plate and the rest of the cord once they have crossed the midline. This behavior can be explained by supposing that the floor plate is a more adhesive substrate than the adjacent regions of the cord (Bovolenta and Dodd, 1990). Growth cones would traverse from the ipsilateral ventral cord to the floor plate, since the growth cones will readily cross into more adhesive territory. When these growth cones encounter the contralateral border of the floor plate and the ventral cord, they would turn and extend along that boundary, since they will not cross into less adhesive territory. Ihe fact that commissural growth cones always turn anteriorly may further suggest that the increased adhesivity of the floor plate encountered by the growth cones on the ipsilateral side can overcome the anterior directional cues.

The behavior of CoPA growth cones in the zebrafish spinal cord is more complex but a similar hypothesis can explain their behavior as well. CoPA growth cones turn anteriorly in the floor plate after crossing the ventral midline, but extend beyond the floor plate and along a diagonal pathway (rostral and dorsal) to reach the contralateral dorsal cord (Figure 1). If prior to contact with the midline floor plate cells the ventral cord was more adhesive than the dorsal cord for CoPA growth cones, but following contact with the midline floor plate cell these growth cones changed their affinities for substrates, then one can account for their behavior. For example, CoPA growth cones may change after a delay so that they now find the floor plate inhibitory rather than adhesive, and/or the more dorsal portions of the cord may now be more attractive. The delay would ensure that growth cones cross the ventral midline, and directional information would be provided by structures other than the midline floor plate cell. In the absence of the midline floor plate cells one would expect CoPA growth cones to turn anteriorly but remain in the ventral cord and for growth cones sometimes to fail to cross the midline. In fact most CoPA axons turned anteriorly and remained in the ventral cord for much longer distances after elimination of the midline floor plate cells than they normally do, and they often failed to cross the midline. This hypothesis is obviously not the whole story, since CoPA axons eventually did extend to the dorsal cord (on either the contralateral or the ipsilateral side). It is possible that the change in affinities by the growth cones may eventually occur independently of contact with the midline floor plate cell and that normally the midline floor plate cell provides a precise timing signal for this change. In fact, the expression patterns of two axonal adhesion molecules, TAG-1 and L1, in the spinal cords of rat embryos are consistent with this idea. Commissural axons switch from expressing $T A G-1$ to $L 1$ at the floor plate so that TAG-1 is normally transiently expressed on the initial circumferential portion of the commissural axons prior to contact with the floor plate in vivo (Dodd et 
al., 1988). However, transient expression of TAG-1 can occur without contact with the floor plate in vitro (Karagogeos et al., 1991).

Since VeLD axons often crossed the ventral midline in the absence of the midline floor plate cells, the midline floor plate cells may normally keep these growth cones from crossing the midline. It is possible that VeLD growth cones may normally find the floor plate to be repulsive or less adhesive than the rest of the cord. This would ensure that these growth cones remain ipsilateral. In the absence of the midline floor plate cell, these growth cones can now cross the midline. In this way, the midline floor plate cells may act both to promote CoPA growth cones to cross the midline and extend dorsally on the contralateral side and to prevent VelD growth cones from crossing the midline. In this regard the s-laminin molecule (Sanes et al., 1990) is intriguing because of its localization and differential adhesive properties. S-laminin is found in a subset of basal laminae, including the basal lamina in the floor plate of rat embryos, and is an effective adhesive substrate for some types of neurons but not others.

How directionality information is supplied to spinal growth cones is at present unclear. First, little is known about the nature of directional cues that are normally available near the ventral midline. The midline floor plate cells are unlikely to provide important directionality cues, since a vast majority of CoPA growth cones turn anteriorly despite the absence of these cells. On the other hand, since a significant proportion of VeLD growth cones did make directionality errors, the midline cell may play a more important role in providing directional information to VeLD growth cones than it does to CoP^ growth cones. Second, the directional cues that guide growth cones toward the ventral midline are equally unclear in the zebrafish embryo. Since growth cones extend toward the ventral midline despite the absence of the floor plate, it is not necessary for extension toward the ventral midline. It is possible that a gradient of adhesion along the dorsoventral axis (Holley, 1987) may guide these growth cones toward the ventral midline. Whether, in addition, growth cones can be attracted by the floor plate as in other embryos is unknown.

\section{Multiple Mechanisms May Direct Growth Cones in a Variety of Embryos}

One interpretation of the variable responses of growth cones to the absence of the midline floor plate cells is that multiple cues may operate simultaneously to ensure that growth cones normally follow correct pathways. Multiple, redundant cues that guide growth cones at a choice point may involve one or more molecules expressed by more than one cell or group of cells, or more than one molecule on a single cell or group of cells. In fact the action of multiple cues has been demonstrated at the molecular level in two ways: first, by blocking different adhesion systems, each mediated by specific ligand-receptor in- teractions, with the application of specific antibodies to neurons and glia grown in culture. Blocking any single adhesion system is not sufficient to prevent axonal outgrowth on a glial substrate. Outgrowth can be blocked, however, by blocking several adhesion systems simultaneously (Tomaselli et al., 1988). Second, in Drosophila the genetic elimination of one putative pathfinding cue (the product of the fas-1 or abl gene) proved insufficient to cause obvious errors in axonal outgrowth. Pathfinding errors were observed, however, in a double mutant, defective at both the fas-1 and ab/ gene loci (Elkins et al., 1990).

Multiple cues for growth cone guidance may be inferred in a variety of animals and be a general feature of pathfinding, since growth cones follow both normal and aberrant pathways following elimination of putative pathfinding cues in a number of other cases (Harrelson and Goodman, 1988; Hedgecock et al., 1990; Chitnis and Kuwada, 1991; Raper et al., 1984; Schubiger and Palka, 1985). However, all growth cones need not respond in this fashion following the elimination of putative pathfinding cues. Follower growth cones followed apparently normal pathways but the amount they extended was dramatically decreased after ablation of a set of pioneer axons in the spinal cord of the Japanese medaka fish embryo (Kuwada, 1986). This result is similar to the quantitative decrease in neurite outgrowth seen in antibody block experiments (Chang et al., 1987) and is consistent with the existence of multiple cues as well.

Our results argue that a source of guidance cues exists near the ventral midline in addition to the floor plate cells in the zebrafish spinal cord. This is the case regardless of whether the midline floor plate cells normally induce the lateral floor plate cells or not. If the lateral floor plate cells are induced by the midline floor plate cells, then elimination of the midline cells would be equivalent to elimination of all the floor plate cells. The fact that a significant proportion of axons followed their correct pathways following both elimination of the midline cell alone and elimination of all floor plate cells suggests an additional source of cues. Likewise, if the lateral floor plate cells are not induced by the midline floor plate cells, then our experiments make it unlikely that the lateral floor plate cells provide guidance cues, and the deletion of the midline floor plate cells merely reduces the amount of guidance cue normally provided by all the floor plate cells. Instead, additional cues are likely derived from another source near the ventral midline. Two candidates are the basal lamina on the ventral surface of the floor plate cells (Yaginuma and Oppenheim, 1991; Sanes et al., 1990) and the notochord that is just ventral to this basal lamina. In the case of the former, two candidate sources of the basal lamina-embedded molecules would be either the floor plate cells or the notochord. Of these two cell types, the notochord may be more likely, since the midline floor plate cells appear never to develop in cyc-1 embryos (Hatta et al., 1991). 
The role of the notochord for guidance of growth cones at the ventral midline is unclear. The anterior region of the neuraxis of $S d$ mouse mutants is sometimes missing the notochord but not the floor plate (Bovolenta and Dodd, 1991). In these regions the pattern of anti-TAG-1-labeled commissural axons in cross sections of the spinal cord appeared identical to those taken from sibling wild-type embryos. This likely demonstrates that the initial circumferential portions of commissural axons to the floor plate were not obviously perturbed, but the trajectories of commissural axons once at the floor plate could not be determined from the cross sections that were analyzed. For example, mistakes such as turning ipsilaterally rather than contralaterally or posteriorly rather than anteriorly in the floor plate region by some but not all axons would have been difficult to detect. Therefore, the notochord's role for guidance of growth cones in the floor plate region remains an open question. A combination of notochord ablation and transplantation experiments in both wild-type and cyc-1 embryos should allow one to test whether the notochord is a second source of pathfinding cues in the zebrafish embryo.

\section{Experimental Procedures}

\section{Animals}

Zebrafish embryos were collected from a laboratory breeding colony and maintained according to procedures described previously (Myers et al., 1986).

\section{Labeling of Embryonic Neurons}

The axon trajectories of identified spinal neurons in cyc-1 embryos were assayed in 114 embryos between 18 and $28 \mathrm{hr}$ PF. Neurons were labeled by intracellular injection of the LY dye (59 embryos), backlabeling with the dil dye (Honig and Hume, 1986; 10 embryos), application of MAb CON1 (Bernhardt et al., 1990; 23 embryos), and application of a MAb against acetylated $\alpha$-tubulin (Piperno and Fuller, 1985;22 embryos). In some cases fluorescent label was converted to an electron dense reaction product by photooxidation (Maranto, 1982). The CoPA neurons were labeled in control, wild-type embryos $(n=32)$ at $24-26 \mathrm{hr}$ PF with either LY or MAb CON1.

The effect of ablation of midline floor plate cells was examined in 63 embryos between 21 and $27 \mathrm{hr}$ PF by labeling CoPA and VelD neurons with IY $(n=24)$, dil $(n=21)$, MAb CON1 $(n=$ $29)$, and the MAb against acetylated $\alpha$-tubulin $(n=1)$. The effect of ablation of the lateral floor plate and other ventral cells was examined in 8 embryos with the MAb against acetylated tubulin and in 16 embryos with MAb CON1. The effect of ablation of all the floor plate cells in wild-type embryos and of the two ventral midline cells in cyc-1 embryos was examined with MAb CON1 in 13 wild-type and $19 \mathrm{cyc}-1$ embryos.

\section{Light and Electron Microscopy}

Semithin and ultrathin sections of embryos were prepared and analyzed as described previously (Kuwada et al., 1990a).

\section{Laser Ablations}

Ablations $(n=63$ ) of the midline floor plate cells were performed at 14-16 hr PF, which is 2-5 hr and 0-3 hr before the CoPA and VeLD growth cones, respectively, reach the floor plate. The ablations were centered on spinal segments 7-9 and extended over 3-6 segments. Since ablations at $16 \mathrm{hr}$ coincide with the time the earliest VeLD growth cones reach the floor plate, it is possible that such VeLD neurons are the ones that developed normally. However, not all the normal VeLD axons in experimental seg ments can be due to this possibility, since both normal and aber- rant VeLD axons were found following laser ablation at $14 \mathrm{hr}$, which is at least $2 \mathrm{hr}$ prior to the time VeLD growth cones reach the floor plate.

To ablate specific cells embryos (14-16 hr) were released from the chorion, mounted on their sides on a microscope slide, coverslipped in Earle's balanced salt solution, and placed on the stage of a compound microscope. Targeted cells were ablated by delivering several pulses from a pulsed dye laser focused through the differential interference contrast optics of a com pound microscope. The targeted cells became bloated immediately after delivery of the laser pulses and broke up over a few minutes. After cells were ablated embryos were transferred into Earle's balanced salt solution $\left(28.5^{\circ} \mathrm{C}\right)$ and allowed to develop further.

Cells lateral to the midline floor plate cells were laser ablated in at least 3 segments in each embryo $(n=24)$ at $14-16 \mathrm{hr}$ PF. In each case all CoPA neurons in the experimental segments were normal. The organization of the control side was found to be normal. In particular, there was a distinct motor root in each spinal segment. On the experimental side the success of the ablation was evident by the absence of the motor roots and of VeLD neurons. In some experiments all the floor plate cells in wild-type embryos and the two ventral midline cells in cyc- 7 embryos were ablated. In both wild-type $(n=13)$ and cyc- 7 ( $n=$ 19) embryos ablations were centered in segments $7-9$ and cov ered 3-5 segments.

\section{Analysis of the Trajectory of CoPA Axons}

A measure of the angle of ascent was made by determining the number of segments traversed by these axons from the ventral midline to the point halfway to the DLF along the dorsal-ventral axis. In wild-type embryos axons $(\mathbf{n}=192)$ reached this point after 1.01 segments (range $=0.25-2.75$ segments), with $99 \%$ of axoris reaching this point within 2 segments. We scored all $\mathrm{Co}$ PAs (labeled with either LY or MAb CON1) that had contralateral, ascending axons in laser ablated and cyc-1 embryos as ventral/ ascending if they had halfway points greater than 2 segments or is normal if the halfway points were no greater than 2 segments Furthermore, we quantitatively analyzed the axon trajectories of CoPA neurons from one of the two clutches of cyc- 7 embryos labeled with MAb CON1. In these embryos, ipsilateral CoPA axons $(n=18)$ reached this point after 2.43 segments (range =1.0-3.75 segments) and contralateral, ascending CoPA axons ( $\mathrm{n}=$ 44) after 1.92 segments (range $=0.5-4.0$ segments). The halfway points of both ipsilateral, ascending (Student's $t$ test, $t=10.97$ $P<0.0001$ ) and contralateral, ascending axons (Student's t test $t=8.77, P<0.0001)$ were significantly different from the halfway point of wild-type CoPA axons.

Although similar trajectories were seen following laser abla tion of the floor plate cells as in cyc-1 embryos, a much higher proportion of CoPA axons ascended for abnormally long distances in the ventral cord following laser ablation compared with ipsilateral, ascending axons. This difference may be due to several factors. First, since the midline cells were ablated 2-4 hr prior to the arrival of the CoPA growth cones, it is possible that degeneration products may have contributed to the higher incidence of ventral, ascending and descending axons. In cyc- $1 \mathrm{em}$ bryos such degeneration is unlikely to be involved, since there were no signs of degeneration at the ventral midline at this same time period (see Results). However, control ablations demon strated that degeneration per se does not induce errors by CoPA axons (see Results). Second, although in every case that the specificity of our ablations was examined the ablations were found to be restricted to the midline floor plate cells, we cannot strictly rule out that in some cases laser ablations may have had more extensive effects. For example, the basal lamina underlying the midline cells may have been altered in some way undetectable with electron microscopy or cells adjacent to the midline floor plate cell may have been damaged in addition to removal of the midline floor plate cells. If this were the case, then these additional structures and/or cells may specify direction, since CopA axons rarely made mistakes in direction in cyc-7 embryos. However, neither damage of the cells lateral to the midline floor 
plate cells alone nor damage per se in the ventral cord can account for aberrant pathways taken by CoPA axons following removal of the midline floor plate cell (see Results).

\section{Identification of VeLD Neurons}

In cyc-1 and wild-type embryos following laser ablation of the midline floor plate cells, VeLD neurons were distinguished from Kolmer-Agduhr cells, another class of interneurons found in the ventral cord of amphibians (Dale et al., 1987) and zebrafish (unpublished data; S. Wilson, personal communication) that could potentially be confused with aberrant VeLD neurons by a number of criteria. The Kolmer-Agduhr cell has an ascending axon that initially projects straight anteriorly from the ventral side of the cell body, is recognized by antibodies against $\gamma$-aminobutyric acid, and possesses a ciliated process that contacts the central canal. All the neurons identified as VeLD neurons had axons that initially projected ventrally and did not have processes that contacted the central canal.

\section{Acknowledgments}

We thank C. Kimmel and K. Hatta for supplying us with the cyc-1(b16) mutant line, G. Piperno for the MAb against acetylated $a$-tubulin, V. Lee for the MAb RMO-270, P. Knafl for technical assistance, D. Bay for photography, M. J. Bastiani and S. Wilson for critical reading of the manuscript, and R. I. Hume for helpful discussions. This work was supported by grants from the National Institutes of Health (NS24848) and the March of Dimes Birth Defects Foundation (5-687). R. R. B. is a postdoctoral fellow of the Schweizerischer Nationalfonds zur Foerderung der wissenschaftlichen Forschung, and J. Y. K. is a Basil O'Connor Scholar of the March of Dimes Birth Defects Foundation.

The costs of publication of this article were defrayed in part by the payment of page charges. This article must therefore be hereby marked "advertisement" in accordance with 18 USC Section 1734 solely to indicate this fact.

Received October 3, 1991; revised January 27, 1992.

\section{References}

Baker, R. C. (1927). The early development of the ventral part of the neural tube of Amblystoma. J. Comp. Neurol. 44, 1-27.

Bernhardt, R. R., Chitnis, A. B, Lindamer, L., and Kuwada, J. Y. (1990). Identification of spinal cord neurons in embryonic and larval zebrafish. J. Comp. Neurol. 302, 607-616.

Bovolenta, P., and Dodd, J. (1990). Guidance of commissural growth cones at the floor plate in embryonic rat spinal cord. Development 109, 435-447.

Bovolenta, P., and Dodd, J. (1991). Perturbation of neuronal differentiation and axon guidance in the spinal cord of mouse em bryos lacking a floor plate: analysis of Danforth's short-tail mutation. Development 113, 625-639.

Chang, S., Rathien, F. G., and Raper, J. A. (1987). Extension of neurites on axons is impaired by antibodies against specific neural cell surface glycoproteins. J. Cell Biol. 104, 355-362.

Chitnis, A. B., and Kuwada, J. Y. (1990). Axonogenesis in the brain of zebrafish embryos. J. Neurosci. 10, 1892-1905.

Chitnis, A. B., and Kuwada, J. Y. (1991). Elimination of a brain tract increases errors in pathfinding by follower growth cones in the zebrafish embryo. Neuron 7, 277-285.

Clarke, J. D. W., Holder, N., Soffe, S. R., and Storm-Mathisen, J (1991). Neuroanatomical and functional analysis of neural tube formation in notochordless Xenopus embryos; laterality of the ventral spinal cord is lost. Development 112, 499-516.

Dale, N., Roberts, A., Ottersen, O. P., and Storm-Mathisen, J. (1987). The morphology and distribution of 'Kolmer-Agduhr cells', a class of cerebrospinal-fluid-contacting neurons revealed in the frog embryo spinal cord by CABA immunohistochemistry. Proc. R. Soc. Lond. (B) 232, 193-203.

Dodd, J., and Jessell, T. M. (1988). Axon guidance and the pat- terning of neuronal projections in vertebrates. Science $242,692-$ 699.

Dodd, I., Morton, S. B., Karagogeos, D., Yamamoto, M., and Jessell, T.M. (1988). Spatial regulation of axonal glycoprotein expression on subsets of embryonic spinal neurons. Neuron 1, 105116 .

Eisen, J. S. (1991). Determination of primary motoneuron identity in developing zebrafish embryos. Science 252, 569-572.

Elkins, T., Zinn, K., McAllister, L., Hoffmann, F. M., and Coodman, C. S. (1990). Genetic analysis of a Drosophila neural cell adhesion molecule: interaction of fasciclin I and Abelson tyrosine kinase mutations. Cell 60, 565-575.

Goodman, C. S., Bastiani, M. J., Doe, C. Q., du Lac, S., Helfand, S. L., Kuwada, J. Y., and Thomas, J. B. (1984). Neuronal recognition during development: cellular and molecular approaches. Science $225,1271-1279$.

Harrelson, A. L., and Goodman, C. S. (1988). Growth cone guidance in insects: fasciclin II is a member of the immunoglobulin superfamily. Science 242, 700-708.

Hatta, K., Kimmel, C. B., Ho, R. K., and Walker, C. (1991). The cyclops mutation blocks specification of the floor plate of the zebrafish central nervous system. Nature 350, 339-341.

Hedgecock, E. M., Culotti, J. C., and Hall, D. H. (1990). The unc-5, unc- 6 , and unc- 40 genes guide circumferential migrations of pioneer axons and mesodermal cells on the epidermis in C. elegans. Neuron 4, 61-85.

Holley, J. A. (1987). Differential adhesivity of neuroepithelial cells and pioneering circumferential axons. Dev. Biol. 123, 389-400.

Horig, M. G., and Hume, R. I. (1986). Fluorescent carbocyanine dyes allow living neurons of identified origin to be studied in long-term cultures. J. Cell Biol. 103, 171-187.

Jessell, T. M., Bovolenta, P., Placzek, M., Tessier-Lavigne, M., and Dodd, J. (1989). Polarity and patterning in the neural tube: the origin and function of the floor plate. In Cellular Basis of Morphogenesis. Ciba Foundation Symp. 144, 255-280.

Karagogeos, D., Morton, S. B., Casano, F., Dodd, J., and Jessell, T. M. (1991). Developmental expression of the axonal glycoprotein TAG-1: differential regulation by central and peripheral neurons in vitro. Development 172, 51-67.

Kimmel, C. B. (1989). Genetics and early development of zebrafish. Trends Genet. 5, 283-288

Kuwada, J. Y. (1986). Cell recognition by neuronal growth cones in a simple vertebrate embryo. Science 233, 740-746.

Kuwada, J. Y., Bernhardt, R. R., and Chitnis, A. B. (1990a). Pathfinding by identified growth cones in the spinal cord of zebrafish embryos. J. Neurosci. 10, 1299-1308.

Kuwada, J. Y., Bernhardt, R. R., and Nguyen, N. (1990b). Development of spinal neurons and tracts in the zebrafish embryo. J. Comp. Neurol. 302, 617-628.

Landmesser, L. (1986). Axonal guidance and the formation of neuronal circuits. Trends Neurosci. 9, 489-492.

Maranto, A. R. (1982). Neuronal mapping: a photooxidation reac tion makes Lucifer yellow useful for electron microscopy. Science 217, 953-955.

Myers, P. Z., Eisen, J. S., and Westerfield, M. (1986). Development and axonal outgrowth of identified motoneurons in the zebrafish. J. Neurosci. 6, 2278-2289.

Piperno, $\mathrm{C}_{-}$, and Fuller, M. T. (1985). Monoclonal antibodies specific for an acetylated form of alpha-tubulin recognize the antigen in cilia and flagella from a variety of organisms. J. Cell Biol. 101, 2085-2094.

Placzek, M., Tessier-Lavigne, M., Jessell, T. M., and Dodd, J. (1990). Orientation of commissural axons in vitro in response to a floor plate-derived chemoattractant. Development 110, 19-30. Raper, J. A., Bastiani, M. J., and Goodman, C. S. (1984). Pathfind ing by neuronal growth cones in grasshopper embryos. IV. The effects of ablating the $A$ and $P$ axons upon behavior of the $G$ growth cone. J. Neurosci. 4, 2329-2345. 
Sanes, J. R., Hunter, D. D., Green, T. L., and Merlie, J. P. (1990). S-laminin. Cold Spring Harbor Symp. Quant. Biol. 55, 419430. Schubiger, M., and Palka, J. (1985). Genetic suppression of putative guidepost cells: effect on establishment of nerve pathways in Drosophila wings. Dev. Biol. 708, 399-410.

Szaro, B. G., Lee, V. M.-Y., and Gainer, H. (1989). Spatial and temporal expression of phosphorylated and non-phosphorylated forms of neurofilament proteins in the developing nervous system of Xenopus laevis. Dev. Brain Res. 48, 87-103.

Tessier-Lavigne, M., Placzek, M., Lumsden, A. G. S., Dodd, J., and Jessell, T.M. (1988). Chemotropic guidance of developing axons in the mammalian central nervous system. Nature 336, 775-778.

Tomaselli, K. J., Neugebauer, K. M., Bixby, J. L., Lilien, J., and Reichardt, L. F. (1988). N-cadherin and integrins: two receptor systems that mediate neuronal process outgrowth on astrocyte surfaces. Neuron 1, 33-43.

Yaginuma, H., and Oppenheim, R. W. (1991). An experimental analysis of in vivo guidance cues used by axons of spinal interneurons in the chick embryo: evidence for chemotropism and related guidance mechanisms. J. Neurosci. 17, 2598-2613. 